\title{
Medical associations: Are they outdated or still relevant?
}

Gerald B. Brock, MD, FRCSC

CUA President

Cite as: Can Urol Assoc J 2017; Epub ahead of print. http://dx.doi.org/10.5489/cuaj.5015

Published online November 1, 2017

***

In the mid-1950s, $75 \%$ of all U.S.-based physicians were members of the American Medical Association. More recent figures show that this number has decreased to below 15\% and continues to decline. Is it the cost, their lack of relevance, or are there just too many associations, subspecialty groups, and meetings. Truly it's a cultural phenomenon where the idea of joining large groups or organizations is less appealing to many; as an example, the number of young boys joining the Boy Scouts is also in rapid decline.

At the Canadian Urological Association, we recognize that we must earn your membership on a daily basis by providing services and programs that are relevant to your needs and that are both time- and cost-efficient. We acknowledge that we are competing with many other specialty and subspecialty societies and associations at your hospital, your region, and within your province.

It is with that knowledge as a background that over the past few months we have been working hard to assess current operations at the highly successful and productive Office of Education. We are doing this via needs assessments of our membership, discussions with our industry sponsors, and development of a formal strategic plan. The clear long-term objective is to identify key topics most impactful to the practicing urologist and to provide state-of-theart continuing professional development. The Royal College's direction towards determining competency of our residents in training will likely evolve from our trainees into similar requirements for practicing urologists. With that in mind, we are proactively creating educational initiatives directed at our membership so that we have the capacity to protect our members from any future educational requirements.

Our winter executive meeting, an event held each January in in Montreal, is just around the corner. There, your executive members review activity and determine goals of the association for the next few months. It is also a time where we hope to share feedback from you, the membership of what new services and products you want us to develop. Please feel free to send Tiffany Pizioli, our Executive Director (Tiffany.Pizioli@cua.org), or myself (President@cua.org) or any other member of the executive (http://www.cua.org/en/aboutcua) an email with what you'd like us to do to enhance your practice or to provide a new or different service. 
The final touches are now being laid for the upcoming CUA Annual Meeting in Halifax, where we have an exciting, interactive program with an amazing cohort of excellent international speakers.

I look forward to seeing you in Halifax! 